Gut and Liver, Vol. 11, No. 5, September 2017, pp. 604-611

\title{
Endoscopic Management of Peri-Pancreatic Fluid Collections
}

\author{
Hon Chi Yip and Anthony Yuen Bun Teoh \\ Department of Surgery, Prince of Wales Hospital, The Chinese University of Hong Kong, Hong Kong SAR, China
}

In the past decade, there has been a progressive paradigm shift in the management of peri-pancreatic fluid collections after acute pancreatitis. Refinements in the definitions of fluid collections from the updated Atlanta classification have enabled better communication amongst physicians in an effort to formulate optimal treatments. Endoscopic ultrasound (EUS)-guided drainage of pancreatic pseudocysts has emerged as the procedure of choice over surgical cystogastrostomy. The approach provides similar success rates with low complications and better quality of life compared with surgery. However, an endoscopic "step up" approach in the management of pancreatic walled-off necrosis has also been advocated. Both endoscopic and percutaneous drainage routes may be used depending on the anatomical location of the collections. New-generation large diameter EUS-specific stent systems have also recently been described. The device allows precise and effective drainage of the collections and permits endoscopic necrosectomy through the stents. (Gut Liver 2017;11:604-611)

Key Words: Pancreatic pseudocyst; Pancreatic necrosis; Endosonography; Endoscopic ultrasound-guided pseudocyst drainage; Endoscopic necrosectomy

\section{INTRODUCTION}

Peri-pancreatic fluid collections is a common complication after acute pancreatitis, with a reported incidence of 30\% to $60 \% .^{1-4}$ It may cause symptoms of pain, bleeding or gastric outlet obstruction. Management of peri-pancreatic fluid collections has changed significantly over the past decade and endoscopic techniques are increasingly utilized in the management of these conditions. Increased understandings of the condition have also led to refinements in the definitions in the updated Atlanta's classification. This review aims to provide an overview on the management of peri-pancreatic fluid collections with particular focus on newer endoscopic interventions.

\section{HISTORICAL DEVELOPMENT}

The history of endoscopic treatment of peri-pancreatic collections began in $1975 .^{5}$ In the first report, a 31-year-old woman with history of alcoholism had repeated admissions for abdominal pain. Upper gastrointestinal series showed a 10$\mathrm{cm}$ mass with pressure effect onto the stomach, suspicious of a pancreatic pseudocyst. Endoscopic aspiration was performed with a 21-gauge needle that yielded $60 \mathrm{~mL}$ of yellow to brown color cloudy fluid. Although the cyst recurred soon afterwards, this was the first report of an attempted endoscopic treatment of pancreatic pseudocysts and the start of many in the years to come. Since then, over the last two decades, we have witnessed the evolution of endoscopic treatment from simple aspiration, fistulotomy, nasocystic catheter drainage, endoscopic ultrasound (EUS)-guided puncture to irrigation, necrosectomy, insertion of metallic stents, multiple gateway access techniques and the development of EUS specific stent systems (Fig. 1).

Endoscopic drainage could be the preferred approach of drainage of peri-pancreatic fluid collections if it could overcome a number of obstacles. First, the approach needs to provide a high precision in drainage. The drainage portal must also be of sufficient size to allow adequate decompression. Furthermore, repeated interventions through the portal should be possible and the risk of adverse events associated with the procedure should be low.

\section{DEFINITIONS OF PERI-PANCREATIC FLUID COLLECTIONS}

The Atlanta's classification published in 1992 had been the most utilized classification system for acute pancreatitis. ${ }^{6}$ In 2012, a revised classification system by the acute pancreatitis

Correspondence to: Anthony Yuen Bun Teoh

Department of Surgery, Prince of Wales Hospital, The Chinese University of Hong Kong, 30-32 Ngan Shing Street, Shatin, New Territories, Hong Kong SAR, China

Tel: +852-2632-2627, Fax: +852-2637-7974, E-mail: anthonyteoh@surgery.cuhk.edu.hk

Received on April 4, 2016. Accepted on August 10, 2016. Published online May 12, 2017

pISSN 1976-2283 eISSN 2005-1212 https://doi.org/10.5009/gnl16178

@ This is an Open Access article distributed under the terms of the Creative Commons Attribution Non-Commercial License (http://creativecommons.org/licenses/by-nc/4.0) which permits unrestricted non-commercial use, distribution, and reproduction in any medium, provided the original work is properly cited. 
Evolution of endoscopic drainage

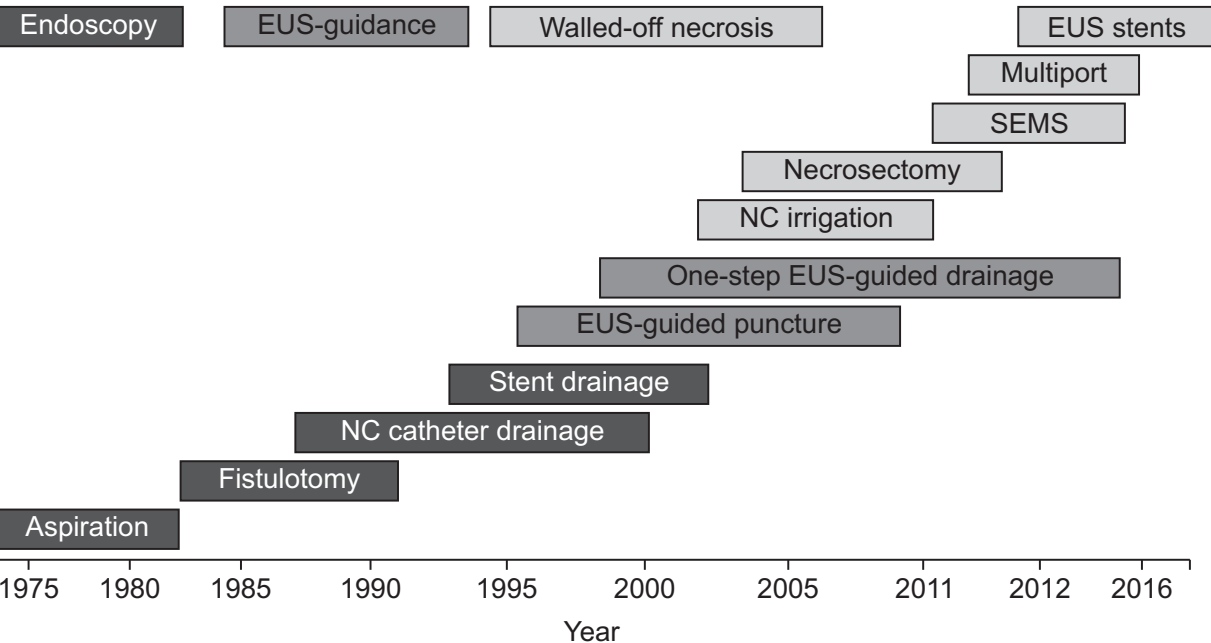

Fig. 1. Evolution of endoscopic treatment of pancreatic fluid collections.

EUS, endoscopic ultrasound; SEMS, self-expanding metallic stents; NC, nasocystic catheter.

Table 1. Revised Atlanta Classification of Pancreatic and Peri-Pancreatic Fluid Collections

\begin{tabular}{|c|c|c|c|}
\hline Type of collection & Time, wk & Location & Imaging appearance \\
\hline \multicolumn{4}{|l|}{ Interstitial edematous pancreatitis } \\
\hline Acute peri-pancreatic fluid collection & $\leq 4$ & Adjacent to pancreas, extrapancreatic only & $\begin{array}{l}\text { Homogeneous, fluid attenuation, } \\
\text { no liquefaction, not encapsulated }\end{array}$ \\
\hline Pseudocyst & $>4$ & Adjacent or distant to pancreas & $\begin{array}{l}\text { Homogeneous, fluid attenuation, } \\
\text { no liquefaction, encapsulated }\end{array}$ \\
\hline \multicolumn{4}{|l|}{ Necrotizing pancreatitis } \\
\hline Acute necrotic collection & $\leq 4$ & In parenchyma and/or extrapancreatic & $\begin{array}{l}\text { Heterogeneous, nonliquefied material, } \\
\text { variably loculated, not encapsulated }\end{array}$ \\
\hline Walled-off necrosis & $>4$ & In parenchyma and/or extrapancreatic & $\begin{array}{l}\text { Heterogeneous, nonliquefied material, } \\
\text { variably loculated, encapsulated }\end{array}$ \\
\hline
\end{tabular}

Adapted from Thoeni RF. Radiology 2012;262:751-764, with permission from Radiological Society of North America. ${ }^{8}$

working group was published. ${ }^{7}$ The most notable difference is the recognition that pancreatic necrosis can exist in both an acute and chronic form, the latter now being defined as walledoff pancreatic necrosis (Table 1). ${ }^{8}$

According to the 2012 updated classification, the following terms have been defined: (1) acute peri-pancreatic fluid collection occurring in interstitial oedematous pancreatitis; (2) pancreatic pseudocyst as a delayed (usually more than 4 weeks) complication of interstitial oedematous pancreatitis; (3) acute necrotic collection in the early phase before demarcation in necrotizing pancreatitis, and (4) walled-off necrosis (WON) being surrounded by a radiologically identifiable capsule which typically develops after 4 weeks from the onset of pancreatitis (Fig. 2).

The new classification scheme provides guidance on the appropriate management of these different conditions. In general, endoscopic drainage is not advised in the early phase of collection formation due to the lack of a well-circumscribed cyst wall. The differentiation between pancreatic pseudocyst and WON is also important as endoscopic drainage of WON had been demonstrated to have significantly lower success rate, higher adverse events, more frequent reinterventions and longer hospital stay. ${ }^{9}$

\section{DRAINAGE OF PANCREATIC PSEUDOCYSTS}

Pancreatic pseudocysts should be drained only if they persist for more than 4 to 6 weeks and are $\geq 6 \mathrm{~cm}$ in size, causing symptoms or complications such as gastric outlet obstruction or biliary obstruction. ${ }^{10,11}$ Drainage of pseudocysts could be performed with surgical, percutaneous and endoscopic approaches. Different endoscopic methods have been employed, including blind endoscopic puncture, endoscopic retrograde cholangiopancreatography (ERCP) or EUS-guided drainage. According to a recent multicenter survey conducted by the Asian EUS group, 77\% of the participating Asian endoscopists preferred EUS-guided approach for pseudocyst drainage. ${ }^{12}$ Regarding the technical aspects of the procedure, a high variation between dif- 

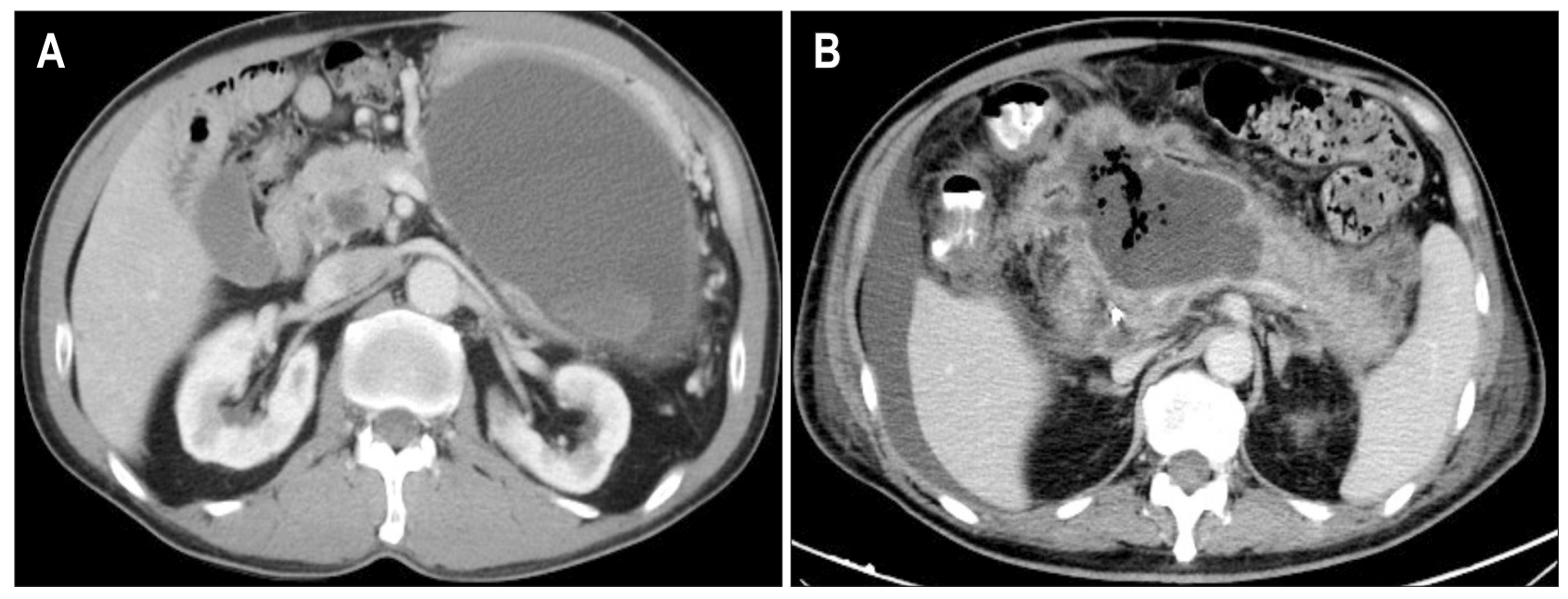

Fig. 2. Computed tomography of (A) pancreatic pseudocyst and (B) walled-off pancreatic necrosis.

ferent centers was observed: 69\% would use double guide-wire technique, $84 \%$ would dilate the track up to 8 to $10 \mathrm{~mm}$ in size, $92 \%$ would place plastic stents instead of metallic stents and $61 \%$ would keep the stents in place for 3 to 6 months. Forty-six percent of participants believed that ERCP is not essential prior to drainage. This highlighted the current lack of consensus on the optimal method of pseudocyst drainage. A recent randomized controlled trial demonstrated that EUS-guided endoscopic cystogastrostomy had equivalent success rate (95\% vs 100\%) yet a shorter hospital stay, lower cost and better quality of life scores as compared to surgical cystogastrostomy. ${ }^{13}$ The blind esophagogastroduodenoscopy (EGD)-guided approach, is limited by the lack of visualization of the pseudocyst during puncture. In a meta-analysis by Panamonta et al., ${ }^{14}$ EUS-guided puncture had a higher technical success rate, particularly for nonbulging type of pseudocysts. A trend to higher risk of hemorrhage was observed with the blind endoscopic approach (2\% to $13 \%$ vs $0 \%$ to $7 \%$ ), but the four studies included were underpowered to detect a statistically significant difference. On the other hand, the benefit of performing ERCP and transpapillary pancreatic ductal drainage in addition to EUS-guided transmural drainage was assessed. ${ }^{15}$ In 174 patients with pseudocysts, 95 received transmural drainage and 79 received combined drainage. Transpapillary drainage was unsuccessful in more than half of the patients with attempted transpapillary stenting. No difference in longterm resolution rates was observed. In addition, transpapillary drainage was negatively associated with pseudocyst resolution, indicating that the presence of a pancreatic stent may hinder the patency and maturation of the cystoenterostomy fistula. Results from a latest systemic review concerning the optimal approaches for pseudocyst drainage concluded that EUS-guided drainage is the modality of choice in pancreatic pseudocysts that are located adjacent to the stomach or duodenum. ${ }^{16}$ In patients with unfavorable anatomy, surgical cystogastrostomy should be the subsequent choice of procedure. Large randomized studies are

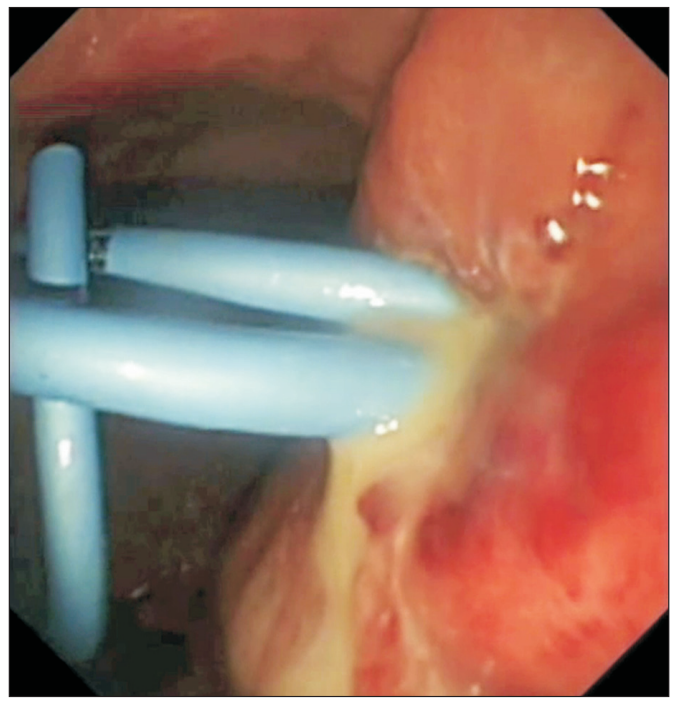

Fig. 3. Endoscopic appearance of an infected pseudocyst after two double pigtail stents were placed.

needed to compare the outcomes of various modalities.

During EUS-guided drainage, the pseudocyst is first visualized using a linear echo-endoscope to determine the best puncture site. In general, transgastric puncture is more preferable than transduodenal puncture owing to more stable position of the endoscope and better luminal visibility in the stomach. Color Doppler mode would be utilized to ensure the absence of aberrant vessels or varices along the intended puncture track. After puncture of the pseudocyst by a 19-gauge needle, the track is dilated with either electrocautery or balloon dilator. One or two double pigtail plastic stents would be placed in the pseudocyst using the double wire technique (Fig. 3). 


\section{ROLE OF ENDOSCOPIC DRAINAGE IN PANCREATIC NECROSIS}

Pancreatic necrosis is traditionally managed by open necrosectomy. The procedure is associated with a high morbidity and mortality. ${ }^{17-28}$ Repeated operations are frequently required. The fashioning of a zipper over the anterior abdominal wall was described to allow repeated access to the peritoneal cavity. ${ }^{28}$ The procedure also posted significant risk of late pancreatic insufficiency. In the recent decade, there has been a paradigm shift on the approach for pancreatic necrosectomy and the procedure is increasing being performed by the endoscopic approach. This could be achieved by either percutaneous retroperitoneal or transgastric approaches. These approaches led to reduced activation of inflammatory markers and local sepsis, thus decreasing the morbidity and mortality associated with the procedure. ${ }^{29}$

Percutaneous retroperitoneal and transgastric endoscopic approaches are complementary to each other, depending on the location of the pancreatic necrosis (Fig. 4). Transgastric approach is more applicable for centrally locating necrosis behind the stomach, whereas the retroperitoneal approach is suitable for necrosis near the pancreatic tail. The transgastric approach avoids the complications associated with percutaneous puncture including bleeding, hollow visceral perforation and the risk of pancreatico-cutaneous fistula. ${ }^{29-32}$ It can provide a more direct approach to the necrotic cavity. However, the presence of an iatrogenic fistula may lead to possible contamination of the abscess cavity by gastrointestinal contents. On the other hand, percutaneous retroperitoneal approach allows introduction of open or laparoscopic surgical instruments for effective necrosectomy. ${ }^{33-35}$ High volume fluid irrigation is possible through large caliber drain for effective necrosectomy and drain output could also be monitored. The "step-up" approach was introduced since the landmark randomized study published by the Dutch group in 2010. ${ }^{36}$ Patients randomized to the "step-up" approach group underwent necrosectomy via the endoscopic approach (percutaneous retroperitoneal or transgastric) if necessary. These patients suffered from significant less major complications. New onset multi organ failure was also significantly reduced with this approach, as were the need for intensive care, new onset diabetes and the rate of incisional hernias. Another smaller randomized trial $(n=22)$ compared the outcomes of transgastric endoscopic necrosectomy and retroperitoneal necrosectomy. ${ }^{29}$ The transgastric endoscopic approach was associated with a significantly less composite end-point of major complications or death. This was mainly attributed by the reduced rate of new onset multiorgan
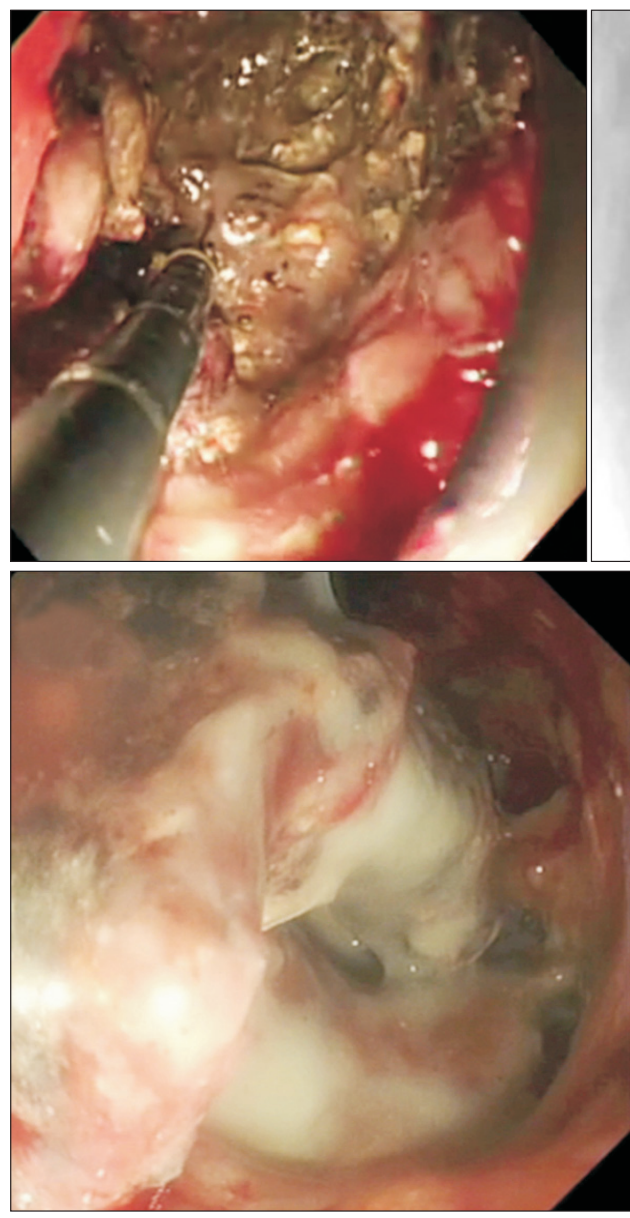
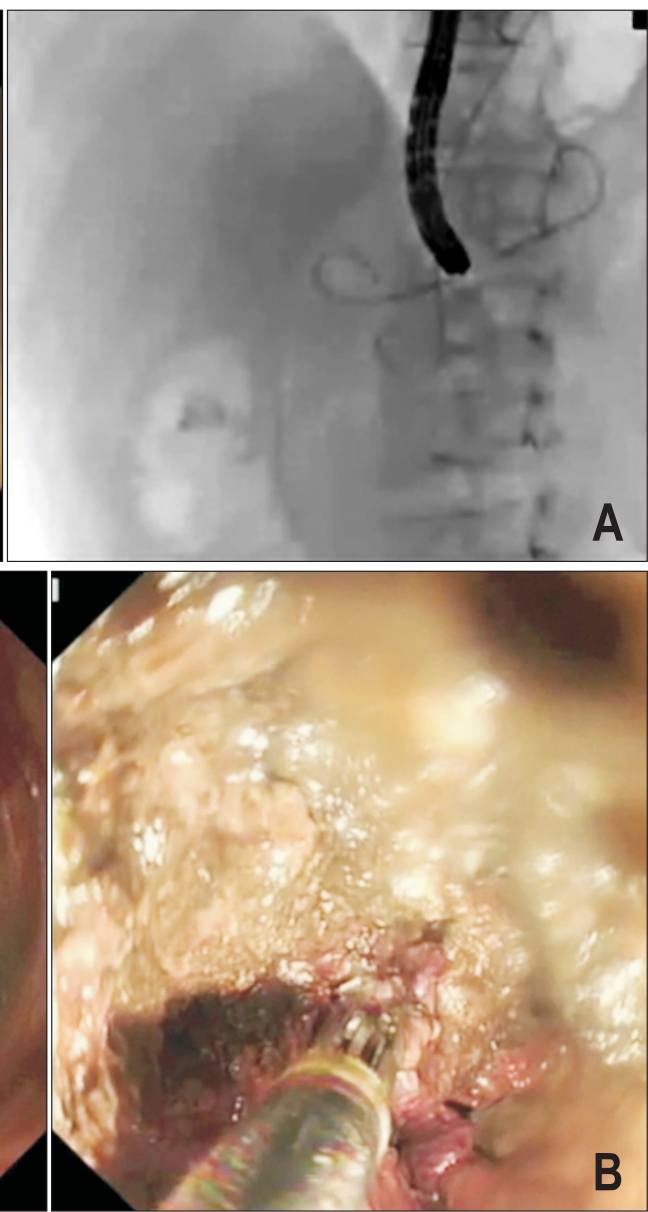

Fig. 4. (A) Transgastric and (B) percutaneous necrosectomy. 
failure and pancreatic fistula with this approach.

Current guidelines suggested that for patients with suspected or confirmed infected necrosis, invasive intervention should be delayed where possible until at least 4 weeks after initial presentation to allow the collection to become "walled-off." ${ }^{37}$ Percutaneous catheter or endoscopic transmural drainage should be the first step in the treatment of patients with suspected or confirmed (walled-off) infected necrotizing pancreatitis, while necrosectomy should be reserved for those who do not improve despite drainage.

\section{RECENT ADVANCES IN ENDOSCOPIC DRAINAGE OF PANCREATIC COLLECTIONS}

EUS-guided drainage is traditionally performed by an oblique viewing echo-endoscope. However, the angle of the instrument channel results in tangential puncturing of the collection. This may lead to inadequate transmission of force during insertion of the stents. Furthermore, re-cannulating an angulated track for multiple stent insertion may be difficult after tangential puncturing. Recently, forward-viewing echo-endoscopes have become available. The device allows forward sonographic imaging with in-line axis for puncturing and insertion of stents along the direction of the scanning plane (Fig. 5). This may allow better transmission of force and easier insertion of stents. In a study involving 58 patients from four tertiary centers comparing forwarding viewing and oblique viewing echo-endoscopes in drainage of pancreatic pseudocyst $>6 \mathrm{~cm}$ in size, no difference in the ease of procedure, procedural time, morbidities and success rates were observed. ${ }^{38}$ It was concluded that forward viewing endoscopes did not provide any addition benefit. However, one should be aware that only expert endoscopists participated in this study, and their performance may be less affected by the types of endoscopes being used.

On the other hand, endoscopic necrosectomy is cumbersome to perform and the procedure is associated with potential risks of morbidities, thus the multiple transluminal gateway technique (MTGT) has been described in an aim to reduce the need of endoscopic necrosectomy. The MTGT involves creation of two to three transmural tracts by use of EUS. A nasocystic catheter would be placed across one of the tract for irrigation of normal saline, while plastic stents would be inserted at the other tracts to facilitate drainage of necrotic content after flushing. In a study of 60 patients with symptomatic walled-off pancreatic necrosis, treatment was successful in $91.7 \%$ of the patients managed by MTGT versus 52.1\% managed by simple continuous drainage. ${ }^{39}$ One patient in the MTGT cohort required endoscopic necrosectomy while in the simple drainage group, 17 required surgery, three underwent endoscopic necrosectomy, and three died of multiple-organ failure. Treatment success was more likely in patients treated by the MTGT after adjusting for confounding factors.

Recently, multiple small cases series have reported the use of metallic stents for drainage of peri-pancreatic fluid collections. ${ }^{40-44}$ These stents provide a larger lumen for drainage and may allow the passage of the endoscope for necrosectomy. The treatment success rate ranged from $78 \%$ to $100 \%$ in these studies using biliary or esophageal metallic stents. However the adverse event rates were also high ranging from 15\% to 33\%. The main problem of conventional metallic stent insertion lies in the lack of anchorage between the stent, gastric wall and the collection. As the collection collapses after successful drainage, the wall of the collection may push the stent outside the cavity and result in stent migration. The stent may also erode onto the pancreatic bed and cause severe bleeding if blood vessels are injured. Nonetheless, the use of metallic stent carries a few important advantages, including the ease of stent insertion, avoidance of multiple guidewires or excessive dilatation, and possibility of intervention through the stent. As a result, a number of specific metallic stent systems have been designed for EUS-guided drainage of pancreatic collections.

EUS specific stent systems represent the latest technological
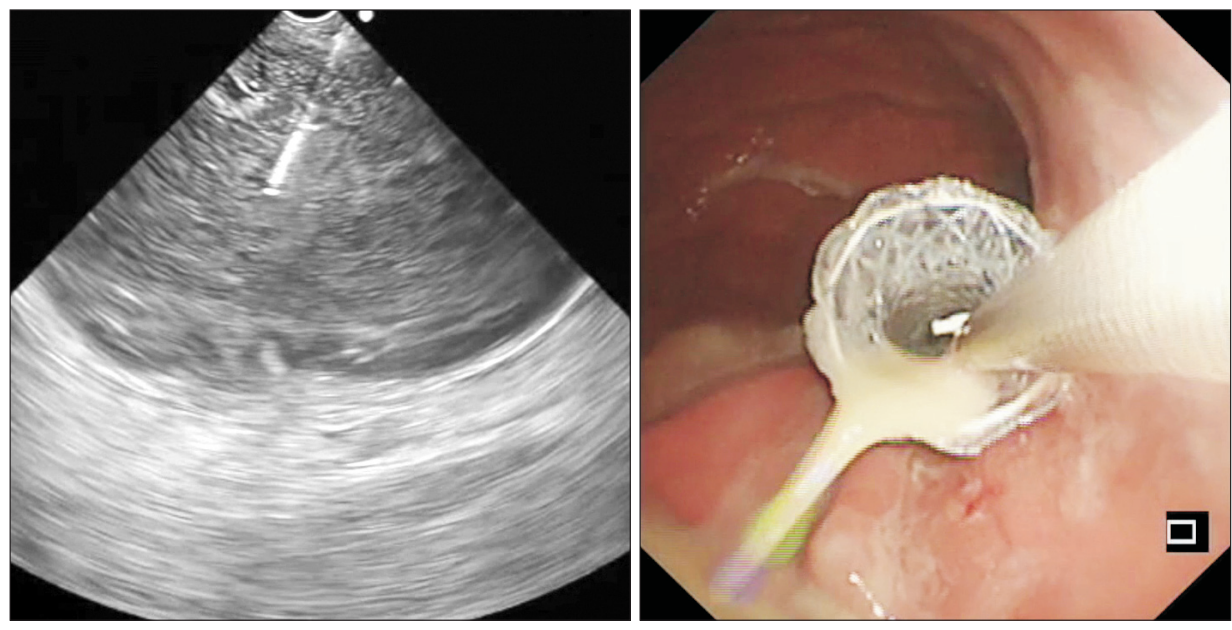

Fig. 5. Drainage with a forward viewing echoendoscope. 

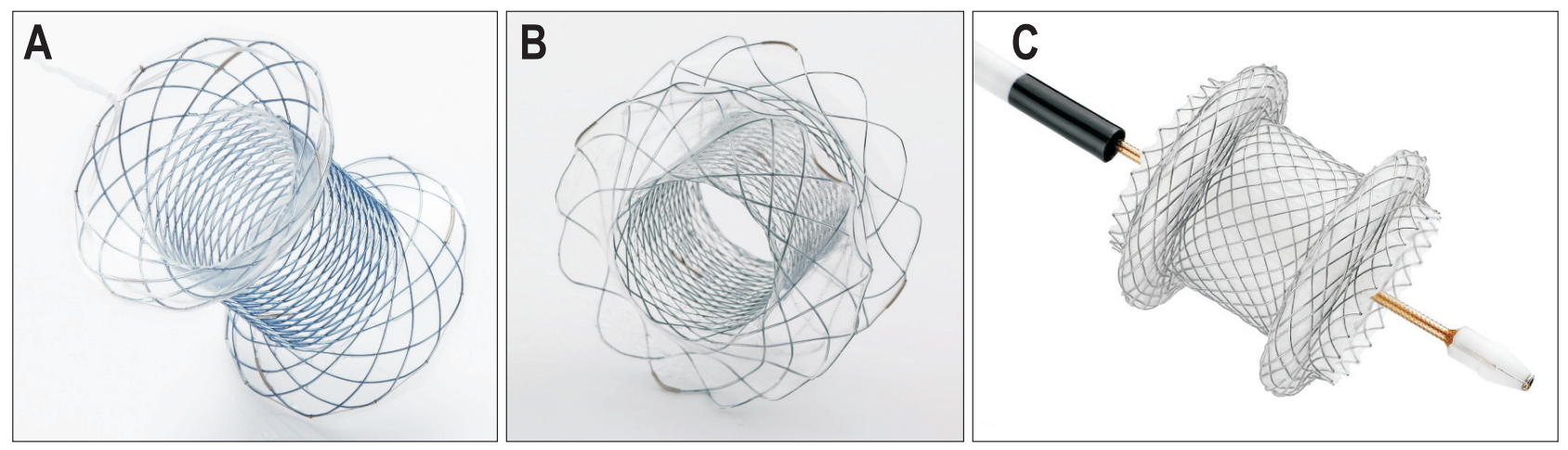

Fig. 6. Endoscopic ultrasound-specific stent systems: (A) NAGI stent, (B) Spaxus stent, and (C) Hot AXIOS stent.

development in EUS-guided drainage (Fig. 6). The described stent systems include the AXIOS stent (Boston Scientific Corp, Marlborough, MA, USA), Niti-S Spaxus stent (Taewoong Medical, Gimpo, Korea) and Niti-S NAGI stent (Taewoong Medical). These systems share several common design elements. Firstly, the stents could be deployed with EUS guidance. The ends of the stents are flanged and short in length to prevent migration. The stents also enjoy a large internal diameter allowing through the stent endoscopic intervention such as necrosectomy. Two of these systems also possess lumen-apposing capabilities to prevent leakage of gastrointestinal contents. An ex-vivo study examining anastomosis created by these stents (gastro-gastrostomy, gastro-jejunostomy, choledocho-gastrostomy, choledochoduodenostomy) demonstrated that the lumen apposing force generated by the AXIOS and Spaxus stents were significantly higher across all types of anastomosis. ${ }^{45}$

Early studies of these EUS specific stent systems yielded promising results. In two studies involving 24 patients with pancreatic pseudocysts, the use of lumen opposing AXIOS stents resulted in a technical success rate of 95.83\% and a clinical success rate of $100 \%{ }^{46,47}$ One patient suffered from complication of stent migration. This was followed by a multitude of studies reporting on the efficacy of lumen apposing stents in pancreatic fluid collections. ${ }^{48-50}$ Another feasibility study also demonstrated $100 \%$ clinical success rate in four patients with pancreatic pseudocysts who underwent EUS-guided drainage by the lumen apposing Spaxus stent. ${ }^{51}$ No adverse event was observed and removal of stent was possible in all patients. In another pilot study utilizing the bi-flanged NAGI stents involving nine patients with pancreatic collections (five pseudocysts and four WON) also reported a 100\% technical success rate with no early complication. ${ }^{52}$ Two patients suffered from late complications of bleeding and stent migration. This was followed by another study that included 47 patients with pseudocyst. The technical and clinical success was $91.48 \%$ and $95.43 \%$ respectively and adverse events occurred in two patients. ${ }^{53}$

On comparing metal stents versus plastic stents for pancreatic fluid collections, results from two studies have become avail- able. $^{54,55}$ Sharaiha et al., ${ }^{54}$ included 230 patients with pseudocysts that received EUS-guided transmural drainage with double plastic pigtail stents or fully covered metallic stents. The uses of plastic stents were associated with lower complete resolution rates (89\% vs 98\%, $\mathrm{p}=0.01)$ but higher procedural adverse events ( $31 \%$ vs $16 \%, \mathrm{p}=0.006$ ). On multivariate analysis, the use of plastic stents was 2.9 times more likely to experience adverse events. Regarding WON, no significant differences in the rates of success, adverse events rates or procedural costs were observed between the two groups. ${ }^{55}$ However, the mean procedure times on initial drainage and re-intervention were significantly shorter for the metal stent group.

\section{CONCLUSIONS}

Tremendous advancements have been made since the first report of endoscopic drainage of peri-pancreatic collections. Endoscopic drainage is now accurate, adequate, safe and effective with potential for repeated interventions. Tools of the trade will continue to evolve and require future trials to confirm their efficacy.

\section{CONFLICTS OF INTEREST}

No potential conflict of interest relevant to this article was reported.

\section{REFERENCES}

1. Kourtesis G, Wilson SE, Williams RA. The clinical significance of fluid collections in acute pancreatitis. Am Surg 1990;56:796-799.

2. Diculescu M, Ciocîrlan M, Ciocîrlan M, Stănescu D, Ciprut T, Marinescu T. Predictive factors for pseudocysts and peripancreatic collections in acute pancreatitis. Rom J Gastroenterol 2005;14:129134.

3. London NJ, Neoptolemos JP, Lavelle J, Bailey I, James D. Serial computed tomography scanning in acute pancreatitis: a prospective study. Gut 1989;30:397-403. 
4. Cui ML, Kim KH, Kim HG, et al. Incidence, risk factors and clinical course of pancreatic fluid collections in acute pancreatitis. Dig Dis Sci 2014;59:1055-1062.

5. Rogers BH, Cicurel NJ, Seed RW. Transgastric needle aspiration of pancreatic pseudocyst through an endoscope. Gastrointest Endosc 1975;21:133-134.

6. Bradley EL 3rd. A clinically based classification system for acute pancreatitis: summary of the International Symposium on Acute Pancreatitis, Atlanta, GA, September 11 through 13, 1992. Arch Surg 1993;128:586-590.

7. Banks PA, Bollen TL, Dervenis C, et al. Classification of acute pancreatitis 2012: revision of the Atlanta classification and definitions by international consensus. Gut 2013;62:102-111.

8. Thoeni RF. The revised Atlanta classification of acute pancreatitis: its importance for the radiologist and its effect on treatment. Radiology 2012;262:751-764.

9. Varadarajulu S, Bang JY, Phadnis MA, Christein JD, Wilcox CM. Endoscopic transmural drainage of peripancreatic fluid collections: outcomes and predictors of treatment success in 211 consecutive patients. J Gastrointest Surg 2011;15:2080-2088.

10. Yeo CJ, Bastidas JA, Lynch-Nyhan A, Fishman EK, Zinner MJ, Cameron JL. The natural history of pancreatic pseudocysts documented by computed tomography. Surg Gynecol Obstet 1990;170:411-417.

11. Bradley EL, Clements JL Jr, Gonzalez AC. The natural history of pancreatic pseudocysts: a unified concept of management. Am J Surg 1979;137:135-141.

12. Teoh AY, Ho LK, Dhir VK, et al. A multi-institutional survey on the practice of endoscopic ultrasound (EUS) guided pseudocyst drainage in the Asian EUS group. Endosc Int Open 2015;3:E130E133.

13. Varadarajulu S, Bang JY, Sutton BS, Trevino JM, Christein JD, Wilcox CM. Equal efficacy of endoscopic and surgical cystogastrostomy for pancreatic pseudocyst drainage in a randomized trial. Gastroenterology 2013;145:583-590.e1.

14. Panamonta N, Ngamruengphong S, Kijsirichareanchai K, Nugent $\mathrm{K}$, Rakvit A. Endoscopic ultrasound-guided versus conventional transmural techniques have comparable treatment outcomes in draining pancreatic pseudocysts. Eur J Gastroenterol Hepatol 2012;24:1355-1362.

15. Yang D, Amin S, Gonzalez S, et al. Transpapillary drainage has no added benefit on treatment outcomes in patients undergoing EUSguided transmural drainage of pancreatic pseudocysts: a large multicenter study. Gastrointest Endosc 2016;83:720-729.

16. Teoh AY, Dhir V, Jin ZD, Kida M, Seo DW, Ho KY. Systematic review comparing endoscopic, percutaneous and surgical pancreatic pseudocyst drainage. World J Gastrointest Endosc 2016;8:310318.

17. Beger HG, Büchler M, Bittner R, Oettinger W, Block S, Nevalainen T. Necrosectomy and postoperative local lavage in patients with necrotizing pancreatitis: results of a prospective clinical trial. World $\mathrm{J}$ Surg 1988;12:255-262.
18. Bradley EL 3rd. A fifteen year experience with open drainage for infected pancreatic necrosis. Surg Gynecol Obstet 1993;177:215222.

19. Sarr MG, Nagorney DM, Mucha P Jr, Farnell MB, Johnson CD. Acute necrotizing pancreatitis: management by planned, staged pancreatic necrosectomy/debridement and delayed primary wound closure over drains. Br J Surg 1991;78:576-581.

20. Függer R, Schulz F, Rogy M, Herbst F, Mirza D, Fritsch A. Open approach in pancreatic and infected pancreatic necrosis: laparostomies and preplanned revisions. World J Surg 1991;15:516-520.

21. Fernández-del Castillo C, Rattner DW, Makary MA, Mostafavi A, McGrath D, Warshaw AL. Débridement and closed packing for the treatment of necrotizing pancreatitis. Ann Surg 1998;228:676684.

22. Beattie GC, Mason J, Swan D, Madhavan KK, Siriwardena AK. Outcome of necrosectomy in acute pancreatitis: the case for continued vigilance. Scand J Gastroenterol 2002;37:1449-1453.

23. Götzinger P, Sautner T, Kriwanek S, et al. Surgical treatment for severe acute pancreatitis: extent and surgical control of necrosis determine outcome. World J Surg 2002;26:474-478.

24. Branum G, Galloway J, Hirchowitz W, Fendley M, Hunter J. Pancreatic necrosis: results of necrosectomy, packing, and ultimate closure over drains. Ann Surg 1998;227:870-877.

25. Connor S, Alexakis N, Raraty MG, et al. Early and late complications after pancreatic necrosectomy. Surgery 2005;137:499-505.

26. Traverso LW, Kozarek RA. Pancreatic necrosectomy: definitions and technique. J Gastrointest Surg 2005;9:436-439.

27. Büchler MW, Gloor B, Müller CA, Friess H, Seiler CA, Uhl W. Acute necrotizing pancreatitis: treatment strategy according to the status of infection. Ann Surg 2000;232:619-626.

28. Tsiotos GG, Luque-de León E, Söreide JA, et al. Management of necrotizing pancreatitis by repeated operative necrosectomy using a zipper technique. Am J Surg 1998;175:91-98.

29. Bakker OJ, van Santvoort HC, van Brunschot S, et al. Endoscopic transgastric vs surgical necrosectomy for infected necrotizing pancreatitis: a randomized trial. JAMA 2012;307:1053-1061.

30. Seewald S, Groth S, Omar S, et al. Aggressive endoscopic therapy for pancreatic necrosis and pancreatic abscess: a new safe and effective treatment algorithm (videos). Gastrointest Endosc 2005;62:92-100.

31. Seewald S, Ang TL, Teng KY, et al. Endoscopic ultrasound-guided drainage of abdominal abscesses and infected necrosis. Endoscopy 2009;41:166-174.

32. Papachristou GI, Takahashi N, Chahal P, Sarr MG, Baron TH. Peroral endoscopic drainage/debridement of walled-off pancreatic necrosis. Ann Surg 2007;245:943-951.

33. Connor S, Ghaneh P, Raraty M, et al. Minimally invasive retroperitoneal pancreatic necrosectomy. Dig Surg 2003;20:270-277.

34. Mui LM, Wong SK, Ng EK, Chan AC, Chung SC. Combined sinus tract endoscopy and endoscopic retrograde cholangiopancreatography in management of pancreatic necrosis and abscess. Surg Endosc 2005;19:393-397. 
35. Carter CR, McKay CJ, Imrie CW. Percutaneous necrosectomy and sinus tract endoscopy in the management of infected pancreatic necrosis: an initial experience. Ann Surg 2000;232:175-180.

36. van Santvoort HC, Besselink MG, Bakker OJ, et al. A step-up approach or open necrosectomy for necrotizing pancreatitis. N Engl J Med 2010;362:1491-1502.

37. Working Group IAP/APA Acute Pancreatitis Guidelines. IAP/APA evidence-based guidelines for the management of acute pancreatitis. Pancreatology 2013;13(4 Suppl 2):e1-e15.

38. Voermans RP, Ponchon T, Schumacher B, et al. Forward-viewing versus oblique-viewing echoendoscopes in transluminal drainage of pancreatic fluid collections: a multicenter, randomized, controlled trial. Gastrointest Endosc 2011;74:1285-1293.

39. Varadarajulu S, Phadnis MA, Christein JD, Wilcox CM. Multiple transluminal gateway technique for EUS-guided drainage of symptomatic walled-off pancreatic necrosis. Gastrointest Endosc 2011;74:74-80.

40. Belle S, Collet P, Post S, Kaehler G. Temporary cystogastrostomy with self-expanding metallic stents for pancreatic necrosis. Endoscopy 2010;42:493-495.

41. Berzosa M, Maheshwari S, Patel KK, Shaib YH. Single-step endoscopic ultrasonography-guided drainage of peripancreatic fluid collections with a single self-expandable metal stent and standard linear echoendoscope. Endoscopy 2012;44:543-547.

42. Fabbri C, Luigiano C, Cennamo V, et al. Endoscopic ultrasoundguided transmural drainage of infected pancreatic fluid collections with placement of covered self-expanding metal stents: a case series. Endoscopy 2012;44:429-433.

43. Penn DE, Draganov PV, Wagh MS, Forsmark CE, Gupte AR, Chauhan SS. Prospective evaluation of the use of fully covered self-expanding metal stents for EUS-guided transmural drainage of pancreatic pseudocysts. Gastrointest Endosc 2012;76:679-684.

44. Weilert F, Binmoeller KF, Shah JN, Bhat YM, Kane S. Endoscopic ultrasound-guided drainage of pancreatic fluid collections with indeterminate adherence using temporary covered metal stents. Endoscopy 2012;44:780-783.

45. Teoh AY, Ng EK, Chan SM, et al. Ex vivo comparison of the lumen-apposing properties of EUS-specific stents (with video). Gastrointest Endosc 2016;84:62-68.

46. Itoi T, Binmoeller KF, Shah J, et al. Clinical evaluation of a novel lumen-apposing metal stent for endosonography-guided pancreatic pseudocyst and gallbladder drainage (with videos). Gastrointest Endosc 2012;75:870-876.

47. Gornals JB, De la Serna-Higuera C, Sánchez-Yague A, Loras C, Sánchez-Cantos AM, Pérez-Miranda M. Endosonography-guided drainage of pancreatic fluid collections with a novel lumenapposing stent. Surg Endosc 2013;27:1428-1434.

48. Rinninella E, Kunda R, Dollhopf M, et al. EUS-guided drainage of pancreatic fluid collections using a novel lumen-apposing metal stent on an electrocautery-enhanced delivery system: a large retrospective study (with video). Gastrointest Endosc 2015;82:10391046.

49. Siddiqui AA, Adler DG, Nieto J, et al. EUS-guided drainage of peripancreatic fluid collections and necrosis by using a novel lumen-apposing stent: a large retrospective, multicenter U.S. experience (with videos). Gastrointest Endosc 2016;83:699-707.

50. Vazquez-Sequeiros E, Baron TH, Pérez-Miranda M, et al. Evaluation of the short- and long-term effectiveness and safety of fully covered self-expandable metal stents for drainage of pancreatic fluid collections: results of a Spanish nationwide registry. Gastrointest Endosc 2016;84:450-457.e2.

51. Moon JH, Choi HJ, Kim DC, et al. A newly designed fully covered metal stent for lumen apposition in EUS-guided drainage and access: a feasibility study (with videos). Gastrointest Endosc 2014;79:990-995.

52. Yamamoto N, Isayama H, Kawakami H, et al. Preliminary report on a new, fully covered, metal stent designed for the treatment of pancreatic fluid collections. Gastrointest Endosc 2013;77:809-814.

53. Dhir V, Teoh AY, Bapat M, Bhandari S, Joshi N, Maydeo A. EUSguided pseudocyst drainage: prospective evaluation of early removal of fully covered self-expandable metal stents with pancreatic ductal stenting in selected patients. Gastrointest Endosc 2015;82:650-657.

54. Sharaiha RZ, DeFilippis EM, Kedia P, et al. Metal versus plastic for pancreatic pseudocyst drainage: clinical outcomes and success. Gastrointest Endosc 2015;82:822-827.

55. Mukai S, Itoi T, Baron TH, et al. Endoscopic ultrasound-guided placement of plastic vs. biflanged metal stents for therapy of walled-off necrosis: a retrospective single-center series. Endoscopy 2015;47:47-55. 